\title{
O COMUNITÁRIO EM TEMPOS DE PÚBLICO NÃO ESTATAL
}

\author{
JoÃo PedRo SCHMIDT*
}

Recebido em: 29 de janeiro de $2010 \quad$ Aprovado em: 02 de fevereiro de 2010

* Doutor em Ciência Política. Professor do Departamento de Ciências Humanas e do Programa de PósGraduação em Direito da Universidade de Santa Cruz do Sul - UNISC. E-mail: jpedro@unisc.br

Resumo: Comunidade e comunitário são termos de larga utilização no discurso de organizações, instituições e atores sociais, tanto no passado como no presente, e caracterizam-se pelo seu caráter polissêmico. No caso brasileiro, distintas iniciativas ao longo da história têm invocado o caráter comunitário. Em comum, a auto-referência ao interesse coletivo e o não pertencimento à esfera estatal. A distingui-las, as variadas perspectivas ideológicas, as diferentes formas de relação com o Estado e a sociedade, os modos de organização interna. A mobilização das instituições comunitárias de educação superior no Brasil em favor de um marco legal próprio reforça o discurso comunitário sob o viés do público não estatal. O presente texto aborda as principais experiências do comunitário na educação brasileira e discute o significado do comunitário como público não estatal.

Palavras-Chave: Comunidade. Instituições comunitárias. Público não estatal. Marco legal das comunitárias.

\section{THE COMMUNITARIAN IN TIMES OF THE NOT STATE-OWNED PUBLIC INSTITUTION}

\begin{abstract}
Community and communitarian are widely used terms, in the past as well as in the present, in the discourse of organizations, institutions and social actors, and are characterized by their polysemous qualities. As with the Brazilian case, distinct initiatives have invoked the communitarian nature throughout history. In common, the self-reference to the collective interest and not being owned by the State. To distinguish them, the varied ideological perspectives, the different ways of interacting with the State and society, the internal forms of organization. The mobilization of the communitarian institutions for higher education in Brazil in favor of their own legal framework, strengthens the communitarian discourse under the not State-owned public perspective. This text approaches the main experiences of the communitarian in Brazilian education and discusses the meaning of the communitarian as a public and yet not state-owned institution.
\end{abstract}

Keywords: Community. Communitarian institutions. Not state-owned public institution. Communitarian legal framework.

\section{INTRODUÇÃO}

O estatismo e o privatismo são modelos de organização política e econômica exauridos, incapazes de dar conta das complexidades da sociedade do conhecimento e dos desafios do desenvolvimento sustentável. A conjuntura política atual constitui um momento privilegiado para o debate sobre modelos inovadores.

A recente crise financeira internacional, que abalou as estruturas do capitalismo globalizado, evidenciou que a primazia conferida ao privado nas últimas décadas, sob hegemonia do ideário neoliberal, além de não assegurar o bem-estar social, não assegura sequer a estabilidade dos mercados. A Queda do Muro 
de Wall Street, em 2008, sepultou o projeto político neoliberal, assim como a Queda do Muro de Berlim, em 1989, marcou o fim do socialismo real do século XX. Nas palavras de Joseph Stiglitz, "a crise de Wall Street é para o fundamentalismo de mercado o que a queda do Muro de Berlim foi para o comunismo: ela diz ao mundo que este modo de organização econômica é insustentável". ${ }^{1}$ Eric Hobsbawn referenda este entendimento ao declarar que as tentativas de realizar as economias modernas na forma do planejamento centralizado do tipo soviético e as desprovidas de restrições e controles da economia capitalista de livre mercado se mostraram infundadas. "A primeira quebrou nos anos 1980, arrastando consigo os sistemas políticos comunistas europeus. A segunda está quebrando diante dos nossos olhos na maior crise do capitalismo global desde os anos 1930." (HOBSBAWN, 2009)

O fracasso do ultraliberalismo e o papel decisivo dos Estados nacionais no enfrentamento da crise financeira de 2008/2009 constituem argumentos poderosos em favor da reafirmação da importância do Estado na vida social, como regulador do mercado e como indutor do desenvolvimento. Superada a miopia do pensamento único, elites políticas, econômicas e intelectuais estão mais propensas a pensar um projeto de novo Estado que seja equidistante do Estado mínimo e do Estado máximo.

Afiguram-se promissoras concepções que colocam a comunidade ao lado do Estado e do mercado como o tripé que sustenta o universo público, próprio do comunitarismo responsivo (ADÁN, 2003); que acolhem o pressuposto de um Estado forte, indutor, regulador e subsidiário (SCHMIDT, 2009); em que o mercado é orientado não só pela competição, mas também pela cooperação (DOWBOR, 2009); e em que a sociedade civil é protagonista na esfera pública ampliada e participa da oferta de serviços públicos. (VIEIRA, 2005)

As instituições comunitárias de caráter público não estatal podem vir a ter uma potência política expressiva caso as estruturas sócio-político-econômicas evoluam nesse sentido. Criadas e mantidas pelas comunidades, orientadas para as necessidades da coletividade, prestadoras de serviços de interesse público na área social (como educação, saúde e assistência social) e sem pertencer à esfera estatal, elas reúnem condições para proporcionar ao país relevantes contribuições ao compartilhar com o Estado e com as organizações da sociedade civil a tarefa de oferecer serviços públicos de qualidade.

O aproveitamento das potencialidades do comunitário no país está travado por razões de cultura política, ainda orientada pela dicotomia público/privado,

1 Cf. entrevista ao jornal El País. Disponível em: $<$ http://www.cartamaior.com.br/templates/materiaMostrar. cfm?materia_id=15251>. Acesso em: 27 de abr. 2009. 
presente tanto nos meios políticos como na sociedade. Não há clareza sobre o que são as instituições comunitárias, sobre o que as distingue das organizações privadas e sobre o caráter público não estatal que reveste grande parte das mesmas. O presente artigo pretende contribuir para elucidar tais questões.

\section{COMUNIDADE, COMUNITÁRIO: TERMOS DE LONGA TRADIÇÃO E COM VARIADOS SENTIDOS}

Comunidade e comunitário são termos utilizados largamente utilizados, por uma variada gama de organizações e agentes sociais, sempre em tom positivo. Os europeus criaram a Comunidade Europeia, à qual está associado o direito comunitário. Governos, partidos e políticos de todos os matizes esforçam-se em mostrar seu compromisso com a comunidade. Empresas e organizações desenvolvem ou incentivam ações comunitárias. Movimentos sociais vão às ruas em nome dos interesses da comunidade. Associações e instituições incluem o comunitário na sua denominação. Grupos rivais de bairros e favelas enfrentam-se em nome da sua comunidade. A comunidade continua no núcleo de grande parte das doutrinas religiosas.

Comunidade é um dos temas clássicos do pensamento ocidental. Está presente no Antigo e no Novo Testamento, na teologia católica, na doutrina socialista, na teoria da subsidiariedade, no chamado comunitarismo asiático e em renovadas formas de comunitarismo dos dias atuais. (ETZIONI, 2003)

Segundo Robert Nisbet (1982), a história da filosofia social é fundamentalmente a história das ideias e dos ideais humanos quanto à comunidade (e à anticomunidade). $\mathrm{O}$ autor sistematiza o pensamento dos filósofos sociais quanto às principais formas de comunidade, cujo protótipo é a família, a saber, as comunidades militar, política, religiosa, revolucionária, ecológica e pluralista, ressaltando que o tema é o principal objeto do pensamento dos filósofos sociais, mesmo que não apareça explicitamente como assunto central.

A comunidade foi confrontada pelo Iluminismo e pelas teorias liberais do contrato social. Sua "redescoberta" acontece no século XIX, envolvendo posições políticas distintas e muitas vezes antagônicas, do conservadorismo de Burke ao socialismo utópico de Proudhon, esteve presente em filósofos do quilate de Hegel e Bergson, permeou o pensamento religioso e reorientou a historiografia. (NISBET, 1998)

A sociologia ocupou-se intensamente do contraste entre a comunidade pré-moderna e a comunidade na sociedade industrial, a partir da distinção de Ferdinand Tönnies entre Gemeinschaft (comunidade) e Geselschaft (socieda- 
de). Nas últimas décadas do século XX, a capacidade explicativa dos estudos sociológicos sobre a comunidade e o valor analítico desse conceito foram fortemente questionados (SHORE, 1996). Mas, isso em nada diminuiu a sua importância prática e a sua utilização no discurso de organizações, instituições e agentes sociais e políticos. Zygmunt Bauman (2003) explica a importância da comunidade na vida humana pelas sensações a ela associadas: ela é uma coisa boa, um lugar cálido, confortável, aconchegante; um lugar seguro, em que há solidariedade, em que podemos esperar ajuda para as nossas necessidades.

$\mathrm{O}$ tema da comunidade continua em destaque no meio acadêmico. Sua vitalidade é atestada particularmente pela produção científica relativa ao capital social e ao comunitarismo, ambas importantes para pensar a relação entre o comunitário e o público não estatal.

O capital social é uma temática amplamente trabalhada no Brasil desde a década de 1990. Tem especial interesse aqui o conceito de comunidade cívica, central nas obras de Robert Putnam (1996). Tomada da tradição republicana, Putnam atribui à comunidade cívica as seguintes características: participação cívica, igualdade política, solidariedade, confiança, tolerância e associativismo. Sustentando que a comunidade cívica é um importante indicador de desenvolvimento e de eficácia institucional, Putnam enfatiza que o capital social é um ingrediente indispensável para a democracia participativa, fertilizada pelo envolvimento ativo dos cidadãos.

O comunitarismo é uma temática de pouco destaque na academia e nos fóruns de debate da sociedade civil brasileira, limitada a certos círculos filosóficos e religiosos. Panorama diverso do de países do capitalismo central, como os Estados Unidos e vários países europeus, onde constitui uma pauta importante de debates nas últimas décadas. Apropriar-se do debate comunitarista ${ }^{2}$, especialmente daquele concernente mais diretamente aos rumos da política, é uma tarefa da pesquisa fundamental para quem se ocupa do tema das instituições comunitárias no país. Afiguram-se particularmente promissoras as formulações

2 O comunitarismo moderno constitui-se na academia anglo-saxã como reação à obra Uma Teoria da Justiça, de John Rawls, em 1971. Autores como Alasdair McIntyre, Michael Sandel, Charles Taylor e Michael Walzer empenharam-se em construir uma crítica à posição liberal de Rawls de que a tarefa central do governo era assegurar liberdade e oportunidades aos indivíduos. Sem assumir o termo comunitarismo, importantes pressupostos do que veio a ser o comunitarismo posteriormente estão presentes na reflexão desses autores, como a reafirmação da natureza social do ser humano, a importância da tradição e do contexto social para a moral e a política, e questões normativas sobre valores e comunidade. Segundo Daniel Bell, a disputa entre liberais e comunitaristas nos anos 1970 e 1980 foi marcada por dois grandes debates: universalismo x particularismo e a natureza do "eu". Nos anos 1990, o comunitarismo, especialmente através de Amitai Etzioni e pesquisadores associados ao The Responsive Community, adquire características diferentes: adentra no terreno político, enfatizando a responsabilidade social e a promoção de políticas voltadas a sustar a erosão da vida comunal e da fragmentação social. Ver: BELL, Daniel. Communitarianism. 2009. In: STANFORD Encyclopedia of Philosophy. Disponível em: $<$ http://plato.stanford.edu/entries/communitarianism $>$. 
de Amitai Etzioni ${ }^{3}$, considerado o principal representante do comunitarismo atual. O comunitarismo responsivo de Etzioni aponta para uma "terceira via", um caminho alternativo entre os extremos da excessiva regulação/controle estatal e do puro mercado. Esse comunitarismo não pretende ser um sistema político e sim um novo paradigma sociológico. Entre suas principais questões e contribuições destacam-se: a relevância da dimensão moral para a construção da boa sociedade; a ênfase no papel da família e da escola para a formação moral; a participação dos cidadãos e das comunidades na cena pública; o equilíbrio entre direitos e responsabilidades; o equilíbrio de poder entre Estado, mercado e comunidades; a ideia de que a esfera pública deve favorecer "megálogos" que incluam o debate racional e moral; a insistência nos princípios do bem comum e da felicidade social; a mensuração da saúde social através de critérios qualitativos estabelecidos pela socioeconomia; o reconhecimento da diversidade cultural, sem abrir mão da busca da unidade através da educação cívica e do diálogo democrático. (ADÁN, 2003; ETZIONI, 2003)

Historicamente, não houve um vínculo necessário entre o comunitário e o público não estatal. Como mostra Alain Touraine (1996), ao longo dos últimos séculos projetos nacionalistas e pretensamente populares que nada tiveram de democráticos apresentaram-se com as vestes do comunitário. O nazismo, por exemplo, popularizou o termo Volksgemeinschaft (comunidade do povo, comunidade nacional), numa perspectiva racista e etnocentrista, frontalmente oposta a qualquer propósito democrático. ${ }^{4} \mathrm{~A}$ formulação de um ideário democrático em que o público não estatal tenha lugar de destaque é uma tarefa intelectual complexa e de alta relevância.

O uso discursivo insistente e a forte polissemia tornam indispensável examinar até que ponto o discurso, a organização interna e a prática social das instituições auto-assumidas como comunitárias são compatíveis com a democracia e com as exigências do público não estatal.

3 Amitai Etzioni, renomado sociólogo norte-americano, professor da The George Washington University, é conhecido no Brasil basicamente pelas suas contribuições à sociologia das organizações e pelo modelo de decisão de políticas públicas de "sondagem mista" (mixxed scanning), desenvolvidas na fase inicial de sua trajetória intelectual. A partir dos anos 1990 torna-se referência internacional do comunitarismo, com obras como The new golden rule (New York: Basic Books, 1996), The spirit of community (New York: Crown Books, 1993), The moral dimension: toward a new economics (New York: Free Press, 1988) e From empire to community: a new approach to international relations (New York: Palgrave Macmillan, 2004). O site do autor é: $<$ http://amitaietzioni.org $>$.

4 Para Hannah Arendt, a propaganda nazi concentrou no conceito de Volksgemeinschaft a visão de que havia um domínio mundial judeu, a ser substituído pelo domínio mundial alemão pela ação chefiada por Hitler: "Essa nova comunidade [...] baseava-se na absoluta igualdade de todos os alemães, igualdade não de direitos, mas de natureza, e na suprema diferença que os distinguia de todos os povos da terra". (ARENDT, 1978, p. 455) 


\title{
3 O COMUNITÁRIO NO BRASIL: SEIS REFERÊNCIAS HISTÓRICAS
}

A polissemia que reveste o termo comunitário está bem manifesta em nosso país no âmbito educacional. Educação comunitária, escola comunitária, mobilização comunitária são termos associados a matrizes teóricas e práticas sociais totalmente distintas.

Marilia Sposito e Vera Ribeiro, em pesquisa sobre a escola comunitária realizada na década de 1980, constataram a variedade de sentidos das escolas comunitárias:

\begin{abstract}
Algumas consideram-se comunitárias porque não têm fins lucrativos, outras porque desenvolvem trabalhos de natureza assistencial ou educativa para comunidades, entendidas como setores da população desprivilegiada, ou mais comumente, a "população carente". Outras são comunitárias porque se voltam para uma integração com o seu entorno, entendido como a população local possivelmente atingida de forma mediata ou imediata, incluindo muitas vezes a ideia de região, figurada como espaço circunscrito geográfica ou culturalmente. Outras são comunitárias porque se estruturam "comunitariamente", ou seja, seus integrantes participam de objetivos comuns e mantém sua interação em função da comunidade de ideias, o que não significa necessariamente gestão democrática ou participativa das instituições. Finalmente, há uma parcela que se autodenomina comunitária porque em certa medida a instituição respondeu a demandas de grupos mais ou menos organizados, articulados em movimentos dos setores espoliados da sociedade brasileira. (SPOSITO; RIBEIRO, 1989 apud SANTOS, 2007, p. 88-89)
\end{abstract}

Os vários sentidos do comunitário estão assentados na diversidade de experiências históricas. Há pelo menos seis referências históricas fundamentais, apresentadas a seguir, que devem ser levadas em conta para entender o discurso comunitário no âmbito educacional e, em boa medida, no âmbito das políticas sociais em geral.

\subsection{Escolas e universidades confessionais}

As escolas confessionais católicas foram os primeiros educandários criados no Brasil. Datam da década de 1550 as primeiras escolas e colégios, criados pelos jesuítas, inicialmente em Salvador, Olinda e São Paulo, difundindo-se depois pelo país, sob o regime do padroado, que vinculava estreitamente o Estado à Igreja Católica. Além da educação formal, os jesuítas implementaram ainda meios de instrução informal dos indígenas. 
$\mathrm{Na}$ década de 1580 aportaram os beneditinos, os carmelitas e os franciscanos, que também se dedicaram à educação. É interessante notar que nessa fase inicial da colonização a educação das escolas católicas era gratuita:

Sendo os colégios e escolas levados por elementos da Igreja financiados pela Coroa, devido ao padroado, podemos dizer que, deste período até a expulsão dos jesuítas, realizou-se no Brasil uma experiência de educação pública e gratuita, embora não estatal (MOURA, 2000, p. 42).

Os únicos cursos superiores existentes no país então eram os cursos de Teologia, nos seminários. Quando da expulsão dos jesuítas em 1759, por obra do Marquês de Pombal, havia no país mais de 70 educandários mantidos por eles. Afastados os jesuítas, houve uma redução do sistema escolar, mas a presença católica na educação continuou mediante outras ordens religiosas e padres seculares, tanto em escolas confessionais como em escolas públicas.

O período imperial iniciou com um parco conjunto de escolas. Levantamento de 1827 indicava "33 escolas oficiais de primeiras letras com 1.105 alunos e 170 escolas particulares primárias". (MOURA, 2000, p. 78) Em 1828 são criados dois cursos de ciências jurídicas e sociais, instalados no Convento de São Francisco, em São Paulo, e no Mosteiro de São Bento, em Olinda. A fase imperial termina com a majoritária presença dos educandários católicos na educação primária, média e superior.

A Proclamação da República em 1889 significou o fim do regime do padroado, com a extinção do vínculo direto da Igreja Católica ao Estado. Manteve-se a liberdade de atuação católica na educação, mas sem o aporte de recursos públicos de antes. Cresceu a presença das escolas públicas no segmento primário, enquanto a Igreja se concentrou na educação secundária. Na década de 1930 estimava-se que três quartos das escolas secundárias eram católicos.

A primeira universidade católica - a PUC do Rio de Janeiro - surgiu em 1946. Por algumas décadas as universidades católicas contaram com recursos públicos. Segundo Moacir Gadotti (1995, p. 6), na época anterior aos anos 1970 "as universidades católicas recebiam recursos públicos que atingiam até $60 \%$ do seu orçamento".

Atualmente os educandários católicos continuam representando um contingente muito expressivo da educação básica e superior do país. Levantamento de 2004 dava conta da existência de 1.340 escolas (1.118 escolas de educação infantil, 852 escolas de ensino fundamental e 852 escolas de ensino médio) ${ }^{5}$

5 Dados apresentados por Peres e Ferreira, (2009). 
(PERES; FERREIRA, 2009) e mais de 50 instituições de educação superior, abrigando mais de 1,5 milhão de estudantes, o que continua lhe conferindo um peso significativo no contexto educacional, embora a tendência nas últimas décadas seja de redução do número de estudantes do segmento.

A educação confessional protestante começou a se estabelecer no país ao final do período imperial, no quadro de crise do regime de padroado que vinculava o catolicismo e o Estado brasileiro. Entre as primeiras escolas protestantes estavam: Instituto Gammon (Lavras, 1869); Mackenzie College (São Paulo, 1870); Colégio Piracicabano (Piracicaba, 1881); Instituto Granbery (Juiz de Fora, 1890); Colégio Americano (Porto Alegre, 1890) (AHLERT, 2006, p. 3). Com a Proclamação da República e a laicização do Estado, a educação protestante expandiu-se no país. Embora não alcance os números das instituições católicas, representa um segmento relevante da educação brasileira.

A comunidade é um elemento central da doutrina cristã. Embora nem todas as instituições confessionais cristãs utilizem explicitamente o comunitário como elemento central de sua identidade, grande parte delas reivindicam o caráter comunitário. As teologias católica e evangélica exaltam o papel central da comunidade na pregação de Jesus e na recepção da mensagem pelos cristãos, o que é atestado pela experiência histórica das primeiras comunidades cristãs. ${ }^{6}$ (SCHNEIDER, 2008). Robson Souza (2008) refere-se à importância do comunitarismo cristão nas últimas décadas, seja através da Teologia da Libertação e das Comunidades Eclesiais de Base, seja através de movimentos sociais e partidos políticos de cunho popular. $\mathrm{O}$ autor cita como autores relevantes para o comunitarismo cristão: Emanuel Mounier, Jacques Maritain, Dom Helder Camara e Henrique de Lima Vaz.

A centralidade da questão da comunidade na identidade das instituições confessionais está comprovada pelo importante papel que tiveram na Constituinte de 1986-1987. Foi a ação coordenada pela Conferência Nacional dos Bispos do Brasil que levou à inclusão do tema do comunitário no texto da Constituição Federal, especificamente no artigo 213. Atualmente há um esforço intelectual em desenvolver a concepção do comunitário público não estatal na ótica confessional, cujo pressuposto central é: é possível ser ao mesmo tempo público e confessional. (FOLLMANN, 2009)

6 "A vida cristã é vivenciada e interpretada como uma vida de fé comunitária. Por isso, um dos elementos fundamentais da comunidade é o inter-relacionamento de seus membros, ou seja, é fundamental con-viver com os outros, viver em comunhão." (SCHNEIDER, 2008, p. 58) 


\subsection{Escolas comunitárias de imigrantes}

O Sul do Brasil, mais propriamente os estados do Rio Grande do Sul e Santa Catarina, abriga uma experiência de organização comunitária singular nas zonas de colonização. Os imigrantes europeus - alemães, italianos, poloneses e outros - chegados ao país no século XIX destacaram-se por um forte associativismo e comunitarismo, gerador de um expressivo estoque de capital social.

Há dois fatores importantes à raiz desse fenômeno comunitário: a herança cultural trazida da Europa e a necessidade de encontrar meios de suprir serviços indispensáveis à coletividade (educação, saúde, estradas, cultura) que o Estado brasileiro não proporcionava à época. A solução encontrada pelos imigrantes e seus descendentes foi o desenvolvimento de uma densa rede de associações e organizações, voltadas a atividades diversas: abertura e conservação de estradas, construção e manutenção de escolas e de igrejas, criação de espaços de entretenimento, de cultura e de lazer, fornecimento de crédito e atendimento de variadas necessidades econômicas. Ao longo das picadas e linhas em que os imigrantes se estabeleceram, os únicos equipamentos públicos disponíveis nas primeiras décadas de colonização foram obra de iniciativas e mutirões comunitários. (VOGT, 2009)

As escolas comunitárias foram um dos experimentos mais destacados desse comunitarismo, que se estendeu por mais de 100 anos - da década de 1920 até o final da década de 1930. Segundo Lucio Kreutz (2000), na década de 1930 havia no Brasil 1.579 escolas nas colônias alemãs; 167 escolas nas colônias italianas; 349 escolas nas colônias polonesas; e 178 escolas nas colônias japonesas. A maior parte dessas escolas estava em solo gaúcho e catarinense.

Um experimento original, segundo Arthur Rambo (1994, p. 87), que não reproduziu algum modelo escolar existente em terras europeias:

os imigrantes aqui chegados não possuíam um modelo estrutural no qual pudessem se inspirar. Traziam, isso sim, a experiência e a certeza de que a escola seria capaz de lhes garantir a integridade cultural e religiosa. $\mathrm{Na}$ pátria de origem as autoridades públicas se encarregavam de toda infraestrutura física e operacional da escola. Como aqui o Estado simplesmente não tinha meios para garanti-la e ao que tudo indica, pouco interesse, coube às comunidades providenciar também por essa parte.

Nas primeiras décadas, as escolas comunitárias eram muito humildes. Os professores eram escolhidos dentre os mais acostumados à leitura e à escrita, as edificações eram precárias, o ensino se fazia na língua de origem por falta de conhecimento suficiente da língua portuguesa, não havia material didático 
apropriado e o que mais se aprendia na escola eram noções elementares de linguagem, de matemática e de religião. Gradualmente, melhorou a infraestrutura das escolas, a capacitação e remuneração dos professores e o aprimoramento dos materiais didáticos. Além da língua de origem, as crianças aprendiam também a língua portuguesa. Nas primeiras décadas do século XX, a escola improvisada das primeiras décadas da colonização havia dado lugar a uma "escola estruturada, dotada de unidade de currículo, orientação uniforme e um professorado profissionalizado". (RAMBO, 1994, p. 41)

A presença das escolas comunitárias assegurou nas zonas de colonização um nível de alfabetização extraordinário para os padrões da época. Um levantamento feito no Rio Grande do Sul na década de 1930 mostrava que a taxa de analfabetismo nessas regiões era de menos de $10 \%$ da população, cerca de quatro vezes menor do que nas demais regiões gaúchas. (VOGT, 2009, p. 63)

A presença da religião e do aspecto étnico foi forte nesses educandários. As Igrejas Católica e Luterana foram grandes incentivadoras das escolas comunitárias, gerindo diretamente muitas delas, e o ensino de religião estava presente em todos os currículos. $\mathrm{O}$ aspecto étnico se manifestava não só através do ensino da língua de origem, mas porque as escolas estavam profundamente vinculadas a toda a vida das comunidades coloniais, constituindo-se em espaço de transmissão e recriação da cultura dessas comunidades. Terciane Luchese (2007) constata que nas zonas de imigração italiana houve três diferentes tipos de escolas: as étnico-comunitárias, preocupadas com a difusão do senso de italianidade; as públicas, mantidas pelo Estado, que substituíram em boa parte as anteriores; e as confessionais, criadas pelas congregações religiosas e muito influentes pela formação de clérigos, freiras e lideranças regionais.

O senso cívico aprendido em boa parte dessas escolas era em primeiro lugar o compromisso com a comunidade do entorno. O comunitarismo dos imigrantes não tinha a democracia como referência central, o que é compreensível ao se considerar a cultura política vigente à época, de traços fortemente autoritários, tanto aqui quanto nos países europeus. A consolidação dos regimes e culturas democráticos em nível internacional ocorreu tão-somente após a Segunda Guerra Mundial, e aqui no Brasil a partir do processo de redemocratização ocorrido da década de 1980.

As escolas comunitárias foram inicialmente incentivadas pelas autoridades brasileiras, depois toleradas e finalmente combatidas. No contexto da Segunda Guerra Mundial e do alinhamento do Brasil ao lado dos Aliados, o Estado Novo promoveu no final da década de 1930 a Campanha de Nacionalização, que se caracterizou pela intenção do abrasileiramento forçado das populações 
coloniais, levando praticamente à extinção das escolas comunitárias e sua substituição por escolas públicas. No Rio Grande do Sul, essa Campanha foi um acontecimento de grandes proporções, atingindo mais de 1.000 educandários apenas nas regiões de colonização alemã.

Especificamente no que tange à nacionalização do ensino, o Estado atuou em duas frentes: de um lado, colocou escolas públicas em locais em que já existiam as comunitárias; de outro lado, criou empecilhos legais para inibir a continuidade dessas escolas. Em 1938 e 1939, leis e decretos de nacionalização, que disciplinavam a licença de professor, o uso de material didático e que culminou na interdição do uso de línguas estrangeiras no ensino, praticamente puseram fim ao funcionamento das escolas comunitárias. (VOGT, 2009, p. 67)

Para Arthur Rambo (1994, p. 79), a nacionalização forçada teve sua razão profunda na hierarquia de direitos relativa à educação. Para o comunitarismo dos imigrantes, o direito primeiro da educação dos filhos cabia aos pais, que a delegavam à escola. A Igreja manifestava seu direito natural na educação escolar no tangente às verdades da fé e dos bons costumes. O Estado ficava em último plano, responsável por zelar pelo bem comum. Para Rambo, a nacionalização, consciente ou inconscientemente, tratou de inverter essa escala: a educação foi tratada primeiramente como assunto do Estado, e a escola como instituição a seu serviço. A família e a Igreja tinham de ajustar-se às exigências do Estado, à revelia da tradição cultural anterior.

A questão acima é relevante para o tema do comunitário enquanto público não estatal. A escala de direitos do comunitarismo colonial certamente não é suficiente para a caracterização do comunitário enquanto público. Por outro lado, é indiscutível que a experiência das escolas comunitárias de imigrantes foi algo extraordinário e a forma como foram extintas é reveladora do perfil autoritário e truculento do Estado brasileiro da época. Ao invés de aproveitar o potencial das escolas comunitárias, o Estado optou por destruir esse potencial. O estatal adversário do comunitário: ao invés de cooperação e sinergia entre Estado e sociedade civil, antagonismo e aniquilamento. Um alerta para os nossos dias, em que a defesa do público estatal ainda leva segmentos da sociedade a desmerecer as organizações da sociedade civil.

\subsection{Desenvolvimento de comunidade}

O desenvolvimento de comunidade foi um ideário formulado no pós- $2^{\mathrm{a}}$ Guerra Mundial na Inglaterra e nos EUA e assumido pelas agências internacionais 
- ONU, UNESCO, OEA -, construído sobre os postulados da social-democracia e orientado para preservar o "mundo livre" da ameaça das ideologias antidemocráticas, especialmente o comunismo. Sob o argumento de que a pobreza é a porta de acesso à propaganda comunista e que a melhoria das condições de vida da população era a melhor forma de enfrentar essa ameaça, foram concebidos os programas de assistência técnica aos países pobres, impulsionados principalmente pelo governo norte-americano, e a esses programas esteve vinculado o desenvolvimento de comunidade. ${ }^{7}$ Um conjunto de iniciativas afinado com a teoria da modernização e o desenvolvimentismo, em que o social é entendido como um ingrediente do desenvolvimento econômico.

O esquema conceitual desse ideário, diz Safira Ammann (2003), se rege pelos pressupostos da harmonia e do equilíbrio social. Com raízes teóricas na sociologia funcionalista, sua categoria chave foi a integração social. Em documento da ONU do ano de 1965, mostra a autora, o desenvolvimento de comunidade é definido como

processo através do qual os esforços do próprio povo se unem aos das autoridades governamentais, com o fim de melhorar as condições econômicas, sociais e culturais das comunidades, integrar essas comunidades na vida nacional e capacitá-las a contribuir plenamente para o progresso do país. (AMMANN, 2003, p. 32)

O governo brasileiro adotou o desenvolvimento de comunidade a partir da década de 1940. Uma série de projetos começou a ser desenvolvida por órgãos governamentais, com apoio das agências internacionais, com o objetivo de integrar os esforços das comunidades com as iniciativas governamentais e de colocar o desenvolvimento social a serviço do desenvolvimento econômico. Entre os projetos, organizações e mobilizações criados ou apoiados pelo desenvolvimento de comunidade entre as décadas de 1950 e 1980, segundo Ammann, estão as Missões Rurais, a Campanha Nacional de Educação Rural, os Conselhos Comunitários, os Centros Rurais Universitários de Treinamento e Ação Comunitária - CRUTACs, o Movimento de Educação de Base - MEB, a Mobilização Nacional contra o Analfabetismo, os Centros Sociais Urbanos, os Conselhos de Comunidades, os Centros de Demonstração, a Extensão Rural, os Centros de Desenvolvimento Social, o Projeto Rondon, entre outros.

7 O desenvolvimento de comunidade é um tema de grande relevância nos Cursos de Serviço Social do Brasil, que foram seus principais difusores e a quem se atribui a elaboração da "técnica de organização social como método profissional e sendo os assistentes sociais os profissionais essenciais em muitos programas de organização e desenvolvimento de comunidade". Nesse sentido, foram organizadas sistematizações de experiências em diversos países com a finalidade de preparar os profissionais com base numa base comum de princípios e diretrizes de ação. (WARE, 1970) 
Na década de 1960, no contexto do crescimento do movimento operário urbano e da proliferação de movimentos políticos reformistas, o viés ideológico inicial do desenvolvimento de comunidade passou a ser fortemente questionado. É o que ocorre, por exemplo, no Movimento de Educação de Base, impulsionado pela Igreja Católica, no qual cristãos de esquerda propõe uma linha de ação em favor de mudanças estruturais na sociedade brasileira. A partir dos anos 1960, estabelece-se um confronto interno entre a linha de ação original (inspirada na concepção da integração social) e a aquela em favor de mudanças estruturais.

Com o advento do Regime Militar de 1964, houve um enrijecimento burocrático e administrativo nas ações do poder público, em que o desenvolvimento de comunidade passou a constituir uma tecnologia executiva da política social governamental, com resultados pouco promissores.

A prática do DC [desenvolvimento de comunidade] identifica-se ora com artifícios e pesquisas, projetos, programas e planos, ora com a execução de processo burocrático de administração de programas nas áreas comunitárias ou liberação de recursos nessas áreas (S0UZA, 1996, p. 48).

O autoritarismo militar gerou, por outro lado, ações comunitárias apoiados por instituições (como a Igreja Católica), movimentos sociais e setores da sociedade civil, de modo que o confronto de linhas de pensamento divergentes permaneceu nas décadas de 1970 e 1980.

A ação governamental continuou pautada pelo viés da integração e do assistencialismo. Em 1970, o Ministério do Interior criou um órgão de coordenação de Programas de Desenvolvimento de Comunidade, com o objetivo geral de fomentar a participação das comunidades no desenvolvimento. O órgão adotou o conceito de desenvolvimento de comunidade formulado pela CEPAL: "instrumento de participação popular e um sistema de trabalho destinado a facilitar a conjugação dos recursos da população e do governo, e obter a maior rentabilidade destes". (AMMANN, 2003, p. 117) Mesmo no período da transição democrática, o desenvolvimento de comunidade continuou sendo considerado a técnica mais adequada para impulsionar o desenvolvimento, inspirando as estratégias do Ministério da Integração. Na Nova República, sob o Governo Sarney, foi criado um órgão inspirado nesse ideário, a Secretaria Especial de Ação Comunitária - SEAC, com uma linha de ação assistencialista.

A partir da década de 1990, o desenvolvimento de comunidade perdeu força nos meios governamentais. Um fator importante nesse sentido foi a consolidação de um novo paradigma de desenvolvimento, cuja principal expressão é o 
Índice de Desenvolvimento Humano - IDH, que substituiu o viés economicista tradicional por um enfoque que valoriza as diversas dimensões humanas e estabelece o bem-estar social como grande critério para avaliar o desenvolvimento. Mas, não é difícil notar que muitos elementos do ideário do desenvolvimento de comunidade ainda se encontram hoje nas políticas públicas e que a tensão entre integração social e transformação social ainda está em pauta nos programas voltados às comunidades.

\subsection{Campanha nacional de escolas da comunidade}

A origem da Campanha Nacional de Escolas da Comunidade - CNEC está num movimento de estudantes em favor da ampliação da rede escolar pública, conhecida como "Campanha do Ginasiano Pobre", iniciado no Recife em 1943. O propósito das lideranças estudantis que iniciaram o movimento era incrementar o acesso à educação num período em que muitos jovens estavam alijados da educação escolar.

Após uma etapa inicial de grandes dificuldades, o movimento conseguiu a partir de 1946 uma forte aproximação com o poder público, recebendo apoio financeiro e passando a contar participação de agentes governamentais em suas atividades. Ronalda Barreto da Silva $(2003)^{8}$ ressalta que foi a aproximação com o governo federal e com diversos governos estaduais e municipais que permitiu sua rápida expansão, em diversos estados da federação. A presença das escolas da CNEC se deu em geral onde havia a ausência de escolas públicas. $\mathrm{O}$ investimento nas escolas cenecistas substituiu muitas vezes o investimento em escolas públicas. No segundo governo de Getúlio Vargas (1951-1954), "em vários estados, o estabelecimento de subvenções dos governos estaduais e municipais foi adotado como medida obrigatória para a instalação de ginásios" e a CNEC passou a contar com recursos previstos no orçamento do Ministério da Educação e Saúde (SILVA, 1993, p. 102). A maior expansão da Campanha ocorreu no governo de Juscelino Kubitscheck, cuja esposa, Sara, foi presidente da entidade. ACNEC passou a se constituir num instrumento da política educacional do país, sendo sua expansão solicitada pelos governos. Os conselhos da entidade passaram a ser ocupados majoritariamente por agentes governamentais e legislativos, além de empresários, militares, religiosos e outros.

No governo de João Goulart não se modificou esse quadro de proximidade com o Estado. O discurso comunitário da Campanha fortaleceu-se, mas o

8 A análise de Ronalda Barreto da Silva assume explicitamente as premissas da dicotomia público x privado, enfoque recusado neste trabalho. Isso não impede que se aproveite aqui muitos aspectos da recuperação da trajetória histórica da CNEC feita pela autora. 
papel da comunidade se restringia basicamente à contribuição minoritária na construção de prédios escolares, à manutenção das escolas e ao pagamento de mensalidades para cobrir parcela dos custos.

O advento do Regime Militar em nada alterou as boas relações entre a CNEC e os governos. Os recursos públicos a ela destinados aumentaram, chegando no ano de 1975 a $97 \%$ do total da receita (SILVA, 1993, p. 121). Na década de 1970 a entidade passou por problemas e seus dirigentes identificaram na tendência estatizante, com a criação de escolas públicas, uma das ameaças a ser enfrentada. A saída para as dificuldades foi buscada na diversificação de atividades, que incluiu a implementação de fazendas-escola, programa de artesanato, serviços de editoração, comunicação social, radiodifusão, escolas agrícolas, centros comunitários rurais, unidades comunitárias de produção, na linha do desenvolvimento de comunidade.

O auge de matrículas foi alcançado em 1984, quando a CNEC teve 474.380 matrículas, em 1.016 municípios, 1.346 escolas e 729 prédios próprios. Até o final daquela década a entidade continuou contando com recursos do orçamento federal. Uma lei de 1989 (Lei 7.891) fixava no orçamento do MEC o valor de 250 cruzados novos por turma de $1^{\circ}$ e $2^{\circ}$ Graus. Um projeto de lei de $1995^{9}$ modificava a base de cálculo dos recursos. $\mathrm{O}$ interessante é que na justificativa do projeto o parlamentar atribuía à CNEC o caráter público não estatal.

Nos anos 1990 a Campanha viu-se diante de um novo quadro face à redução gradual dos recursos públicos. No governo Itamar Franco ainda logrou a obtenção de 40 mil bolsas de estudo para seus estudantes, mas o momento já esteve marcado pelo discurso de disputar espaço no mercado, com a diversificação de atividades, como principal estratégia de sobrevivência. Atualmente, conforme seu site, a entidade possui cerca de 109.000 alunos, em 213 escolas básicas e 23 unidades de educação superior. ${ }^{10}$

A experiência da CNEC até a década de 1990 foi marcada pelo forte vínculo com os governos e estruturas estatais. Sustentada na maior parte por recursos públicos, a entidade viu comprometida a sua autonomia diante do Estado. Agentes governamentais e legislativos ocuparam grande parte dos cargos dos conselhos maiores da entidade. O comunitário restringiu-se a aspectos secundários: construção e manutenção das escolas, e contribuição no sustento das mesmas através de mensalidades. São características próprias de uma organização paraestatal e não de uma pública não estatal. O fim da proteção e do financiamento estatal, marcante a partir da década de 1990, forçou a CNEC a

9 Projeto de Lei no 843/1995, apresentado pelo deputado Alexandre Santos (PSDB/RJ).

10 O site da CNEC é: < www.cnec.br. > Acesso em 20 de ago. 2009 
se reinventar para sobreviver. Uma oportunidade para a afirmação do espírito comunitário em sentido público não estatal.

\subsection{Escolas comunitárias (re) criadas por mobilização popular}

Há um conjunto de escolas comunitárias, presentes em várias regiões do país, principalmente a partir de meados da década de 1970, criadas e mantidas movimentos populares. Outra parcela foi recriada ou revitalizada por mobilizações da comunidade escolar.

As escolas criadas e mantidas por movimentos populares são mais numerosas nos grandes centros urbanos do país e nas regiões Nordeste e Norte. Na origem de muitas delas estão agentes populares identificados com a Teologia da Libertação e do ideário da educação popular referenciado em Paulo Freire. Conforme José Batista Neto (1999, p. 2), é "por força da crise da escola pública que as escolas comunitárias fazem sua aparição. Crise que se constitui de três fenômenos: a insuficiência, a ineficiência e má distribuição espacial das redes públicas de ensino." Sustentadas com recursos materiais e humanos advindos das próprias comunidades ou obtidas pelos movimentos populares, essas escolas comunitárias lembram o esforço das populações de imigrantes no Sul do Brasil para criar a sua rede escolar.

Marlene Oliveira dos Santos (2007, p. 28), ao estudar uma escola de um bairro de Salvador, BA, registra o estereótipo que cerca tais escolas comunitárias: "a escola comunitária ainda é vista como um lugar feio, com estrutura física precária, com professores despreparados, com crianças mal-vestidas, despenteadas e com nariz escorrendo". A partir dos anos 1990, muitos desses educandários buscaram sua incorporação ao sistema educacional, o que gerou a necessidade de atender as exigências legais, especialmente a formação dos professores. Em contrapartida, o poder público passou a ser responsável pelas condições de infraestrutura e remuneração de professores em patamares legalmente estabelecidos.

O financiamento dessas escolas comunitárias continua um problema até hoje. A autora registra que o assunto está na pauta dos debates educacionais desde a década de 1980, opondo defensores e adversários do repasse de recursos públicos para as comunitárias. Na Constituinte de 1986-1987 houve a apresentação de uma proposta pelo Movimento de Defesa dos Favelados e pela Comissão de Justiça e Paz da Bahia e pelo Movimento Negro de Brasília, em favor de verbas públicas para escolas comunitárias voltadas às comunidades carentes ou minoritárias, que não foi acolhida. Persiste a exclusão dessas escolas dos mecanismos governamentais de financiamento da educação, incluindo o 
Fundo Nacional da Educação Básica - FUNDEB, criado em 2006. Segundo Santos (2007, p. 88),

A situação das escolas comunitárias e, consequentemente, da educação das crianças filhas de trabalhadores e moradores dos bairros populares de grandes centros urbanos é muito complexa e difícil de ser resolvida. Sem a pressão popular, as escolas comunitárias continuarão no limbo, sem reconhecimento do poder público, ainda que elas, historicamente, venham assumindo o papel do Estado e do Município na oferta de educação.

No campo da educação vinculada aos movimentos populares é preciso lembrar ainda a educação não-formal, desenvolvida por organizações econômicas populares, escolas produtivas, microempresas, cooperativas e movimentos sociais. Educação que responde a necessidades dos movimentos e das comunidades, desenvolvida sem amarras legais, por agentes diversos e sem orientação educacional uniforme.

O vínculo com os movimentos populares e seu projeto de transformação social é o elo dessa forma de educação comunitária com o ideário da educação popular, sistematizado por Paulo Freire, Moacir Gadotti, Jürgen Zimmer ${ }^{11} \mathrm{e}$ outros. Moacir Gadotti e Francisco Gutierrez (1993) dizem que a educação comunitária é expressão da educação popular, que se caracteriza por estar preocupada principalmente com os excluídos do sistema econômico em busca de melhoria da qualidade de vida. Os autores, todavia, frisam a importância de não se opor a educação não-formal a formal: "Não se pode separar educação comunitária de educação escolar, pois os setores populares da comunidade lutam pela escola pública de qualidade.” (GADOTTI; GUTIERREZ, 1993, p. 15)

Paulo Freire, ao lembrar que educação comunitária é um termo que na América Latina abrigou projetos postos em prática pelas ditaduras militares com financiamento norte-americano (leia-se: o ideário original do desenvolvimento de comunidade), argumenta que a mobilização popular deu origem a uma educação comunitária que se vale de conceitos opostos aos valores conservadores da educação autoritária:

Agora, a educação comunitária defende a organização do ensino pela base, a ligação entre instrução e organização sociopolítica dos pobres. Aprender na comunidade, com ela e para ela, significa usar a história da sua própria região, exteriorizando a cultura do silêncio. Significa aprender a engajar-se na sua própria região, tornando-se

11 Jürgen Zimmer apresenta uma interessante síntese da concepção da educação comunitária na perspectiva da educação popular em “Transforming Community Schools Into Open Learning Communities”. Disponível em: <http://www.unesco.org/education/educprog/lwf/dl/olc_zimmer.pdf.> Acesso em: 23 de nov. 2009. 
consciente da situação sociopolítica e lutando para que sociedades fechadas sejam transformadas em sociedades abertas, uma por uma. (POSTER; ZIMMER, 1995, p. 12)

O outro ramo de escolas comunitárias ligadas à mobilização popular é constituído pelas experiências que, em face à crise institucional de educandários tradicionais, passam por um processo de reformulação ou de criação de nova estrutura escolar, com adoção de um modelo de gestão democrática, de autogestão ou cooperativo. Professores, funcionários, pais e estudantes passam a ter vez e voz nas decisões da escola. Transparência e participação tornam-se valores centrais na relação entre direção e comunidade escolar. Educandários que não têm por finalidade a maximização dos lucros e sim a sustentabilidade das atividades educacionais.

A gestão democrática e participativa não isenta tais educandários de conflitos internos. Após uma fase inicial, em que a convergência de esforços é indispensável para a própria sobrevivência da instituição, as divergências de ideias e interesses tendem a por à prova a democracia e o espírito comunitário que fundamentam o projeto educacional da instituição.

Aparecida Cardoso (1995) analisa a trajetória de uma escola comunitária em Campinas. Descontente com a orientação administrativa e pedagógica da escola particular à qual estava vinculado, um grupo de professores e pais decidiu pela criação da escola comunitária, no final da década de 1970. O projeto pedagógico e administrativo foi construído coletivamente, com maciça participação. Pais e professores eram sócios da escola. A união de todos foi a marca dos primeiros anos. Com o passar do tempo, os conflitos começaram a aflorar, em função de interesses corporativos do professorado, com eclosão de greve, fato que levou à reformulação dos estatutos e redefinição das regras referentes ao poder de decisão. A autora evidencia que apesar das dificuldades inerentes a qualquer organização, o educandário tem estruturas sólidas para levar adiante seu projeto educacional.

Mais do que destacar detalhes de uma determinada experiência de escola comunitária importa ressaltar que o comunitário não exclui o conflito, nem assegura a unidade de todos em todas as questões. O que é característico dessas instituições é o compartilhamento das decisões, a existência de mecanismos internos de tratamento dos conflitos e a de busca de soluções pela via democrática, sem necessidade de recurso à autoridade de um chefe plenipotenciário ou de uma autoridade estatal externa.

Quanto à temática do público não estatal, este quinto segmento da educação comunitária brasileira não tem um discurso unificado. O público não estatal 
não é uma bandeira explicitamente assumida pelo conjunto dos movimentos populares. Mas, de um modo geral, há uma convergência do ideário desses movimentos e o da educação popular, com a concepção do público não estatal, em torno de valores centrais como o compromisso com a coletividade, a participação na esfera pública ampliada e a preservação da autonomia das organizações em relação ao Estado.

\subsection{Universidades comunitárias regionais}

As universidades comunitárias regionais ${ }^{12}$ são uma experiência principalmente gaúcha e catarinense, embora existam algumas instituições semelhantes em outros estados. Sua origem deve-se à capacidade das organizações da sociedade civil e do poder público local de associar-se no esforço de suprir a lacuna de educação superior nas regiões interioranas.

No Rio Grande do Sul, a criação e a consolidação dessas instituições são tributárias da tradição associativa inaugurada ainda no século XIX, particularmente nas regiões de colonização alemã e italiana. $\mathrm{Na}$ ausência de serviços públicos prestados pelo Estado, desenvolveu-se um considerável leque de iniciativas comunitárias, que estão no núcleo do expressivo estoque de capital social gerado historicamente nessas regiões.

As origens das primeiras instituições comunitárias regionais gaúchas estão na década de 1940. Desde a década de 1990 estão organizadas no Consórcio das Universidades Comunitárias Gaúchas - COMUNG ${ }^{13}$, criado oficialmente em 1996. Suas afiliadas congregam mais de 40 campi universitários, abrangem mais de 380 municípios em suas áreas de influência e possuem em torno de 120 mil alunos de graduação e pós-graduação, constituindo o maior sistema de educação superior em atuação no estado. A relação das instituições, com o ano de origem, é a seguinte: Universidade de Cruz Alta - UNICRUZ, 1947; Universidade de Caxias do Sul - UCS, 1949; Universidade da Região da Campanha - URCAMP, 1953; Universidade de Passo Fundo - UPF, 1956; Universidade Regional do Noroeste do Estado do Rio Grande do Sul - UNIJUÍ, 1957; Universidade Católica de Pelotas - UCPel, 1960; Universidade de Santa Cruz do Sul - UNISC, 1962; Universidade Regional Integrada do Alto Uruguai - URI, 1964; Centro Universitário Univates - UNIVATES, 1969; Centro Universitário Feevale - FEEVALE, 1970.

12 Embora se fale usualmente das "universidades" comunitárias regionais do sul do país, a denominação inclui também centros universitários, com características similares.

13 O COMUNG inclui ainda a Universidade do Vale do Rio dos Sinos - UNISINOS e a Pontifícia Universidade Católica do Rio Grande do Sul - PUCRS. 
Em Santa Catarina, o estoque de capital social também foi fator fundamental do surgimento e fortalecimento das comunitárias. Um traço peculiar do modelo comunitário catarinense é a forte presença do poder público local, especialmente das Prefeituras. O enraizamento das instituições nas comunidades regionais assinala Luiz Gonzaga de Lima (2009, p. 95), é comum a todas as instituições: elas

têm como principal mola propulsora e como base de atuação o envolvimento com a sua região e a intenção/missão de ser agente do desenvolvimento regional. Essa característica está já marcada desde a sua criação e inserida mesmo em suas cartas instituidoras.

A relação das instituições catarinenses, com o respectivo ano de origem, é a seguinte: Universidade do Planalto Catarinense, 1959; Universidade do Vale do Itajaí, 1962; Universidade Regional de Blumenau, 1964; Universidade do Sul de Santa Catarina - UNISUL, 1965; Universidade para o Desenvolvimento do Alto Vale do Itajaí - UNIDAVI, 1966; Universidade da Região de Joinvile UNIVILE, 1967; Universidade do Oeste de Santa Catarina - UNOESC, 1968; Universidade do Extremo Sul Catarinense - UNESC, 1968; Universidade do Contestado - UnC, 1970; Universidade Comunitária Regional de Chapecó UNOCHAPECÓ, 1972; Centro Universitário de Brusque - UNIFEBE, 1973; Centro Universitário de Jaraguá do Sul - UNERJ, 1973; Centro Universitário Barriga Verde - UNIBAVE, 1974. As universidades estão organizadas na Associação Catarinense das Fundações Educacionais - ACAFE $^{14}$, fundada em 1974, que congrega 15 fundações educacionais criadas por lei dos poderes públicos municipais e estadual. As universidades atendem no seu conjunto 59 municípios e possuem em torno de 157 mil alunos. O modelo comunitário é apontado pelas autoridades como um dos principais fatores vinculados ao elevado Índice de Desenvolvimento Humano de Santa Catarina e ao posto de segundo lugar em matrículas na educação superior do país.

O período de criação das comunitárias gaúchas e catarinenses - situado entre as décadas de 1940 e 1970 - impede que se estabeleça qualquer vínculo com o projeto político neoliberal, que ganhou terreno a partir da década de 1980. A tese comumente aceita nas ciências sociais de que o crescimento do terceiro setor está associado à desresponsabilização do Estado quanto à oferta de serviços públicos, repassando-a a organizações não governamentais, não cabe aqui. As universidades comunitárias regionais foram estruturadas em

14 AACAFE inclui ainda duas instituições públicas estatais: a UDESC - Universidade do Estado de Santa Catarina e Centro Universitário Municipal São José - USJ. 
plena vigência do Estado desenvolvimentista, suprindo a lacuna de educação superior nas regiões interioranas por iniciativa da sociedade civil e do poder local, e nada tem a ver com as reformas de caráter neoliberal implementadas décadas mais tarde.

As universidades comunitárias regionais do sul do país são as instituições comunitárias em que as características do público não estatal se apresentam de modo mais claro (FRANTZ; SILVA, 2002; MARTINS, 2008; SCHMIDT, 2009). São traços distintivos dessas instituições: criação impulsionada por organizações da sociedade civil e do poder público local, a quem pertence o patrimônio; não estão orientadas para a maximização do lucro, sendo os resultados financeiros reinvestidos na própria universidade; têm profunda inserção na comunidade regional, interagindo com os seus diversos segmentos; os órgãos deliberativos superiores são integrados por representantes dos diversos segmentos da comunidade acadêmica (professores, estudantes e técnicos administrativos) e da comunidade regional; os dirigentes são professores da universidade, eleitos pela comunidade acadêmica e por representantes da comunidade regional; a forma jurídica da mantenedora é a de fundação de direito privado, de associação ou de sociedade civil; o controle administrativo e da gestão financeira é feito pela mantenedora; o patrimônio, em caso de encerramento das atividades, é destinado a uma instituição congênere.

A identidade pública não estatal é um aspecto marcante do discurso das comunitárias gaúchas e catarinenses, reafirmado insistentemente nos documentos das instituições e entidades representativas ao longo das últimas décadas. Enquanto em outras vertentes das comunitárias o público não estatal é um elemento acessório do discurso, no caso das comunitárias regionais esse elemento está no núcleo discursivo. No discurso dessas instituições, o caráter comunitário se expressa especialmente na inserção da universidade na comunidade regional, na relação constante da universidade com a sociedade civil e o poder público regionais, na participação de integrantes da comunidade regional nas decisões da universidade e na gestão democrática das instituições. ${ }^{15}$

\section{AS COMUNITÁRIAS E O PÚBLICO NÃO ESTATAL: O DEBATE SOBRE O MARCO LEGAL}

No âmbito das variadas experiências referidas acima se desenvolveram diferentes discursos acerca da identidade comunitária e da posição diante da dicotomia público/privado. As universidades comunitárias regionais são as

15 Ver neste sentido o relato sintético de cada uma das universidades comunitárias gaúchas e catarinenses na segunda parte do livro Instituições Comunitárias: Instituições Públicas Não-Estatais. (SCHMIDT, 2009) 
que vêm afirmando mais fortemente seu caráter público não estatal. Mas, isso não foi suficiente para impulsionar uma mobilização nacional em prol de um marco legal específico do modelo comunitário. No processo de construção da Constituição de 1988 foram as instituições católicas que tiveram atuação decisiva em prol do reconhecimento do caráter distintivo das comunitárias.

$\mathrm{Na}$ Constituinte de 1986-1987 confrontaram-se duas posições acerca do tema da transferência ou não de recursos públicos para estabelecimentos educacionais que não pertencessem à rede pública. Contra a possibilidade da transferência de recursos foi apresentada uma emenda patrocinada pela Confederação dos Professores do Brasil - CPB, da Associação Nacional dos Docentes do Ensino Superior-ANDES, da União Nacional de Estudantes - UNE, da Central Única dos Trabalhadores - CUT e da Central Geral dos Trabalhadores - CGT, com 279.013 assinaturas. A favor da transferência de recursos públicos para instituições não estatais sem fins lucrativos e que prestassem contas dos recursos recebidos, foi apresentada uma emenda pela Conferência Nacional dos Bispos do Brasil-CNBB, Associação de Educação Católica - AEC e Associação Brasileira das Escolas Superiores Católicas - ABESC, com 750.077 assinaturas. Uma terceira proposta foi apresentada pelo Movimento de Defesa dos Favelados, pela Comissão de Justiça e Paz (ambos da Bahia) e pelo Movimento Negro de Brasília, com 23.042 assinaturas, que visava legitimar como públicas as escolas comunitárias voltadas às comunidades carentes ou minoritárias. (SANTOS, 2007; MARTINS, 2008)

A redação do artigo $213^{16}$ da Constituição Federal acabou contemplando o intento das entidades católicas, ao contemplar a categoria das escolas comunitárias no texto constitucional e possibilitar a transferência de recursos públicos para escolas comunitárias, confessionais ou filantrópicas que comprovem finalidade não lucrativa, apliquem seus excedentes financeiros em educação e assegurem a destinação de seu patrimônio a escola congênere em caso de encerramento de suas atividades. Na educação fundamental e média, os recursos são para bolsas de estudo; na educação superior, para atividades de pesquisa e extensão.

Um segundo momento do debate aconteceu na década de 1990 e teve sentido contrário ao anterior. A Lei de Diretrizes e Bases da Educação - LDB,

16 Art. 213. Os recursos públicos serão destinados às escolas públicas, podendo ser dirigidos a escolas comunitárias, confessionais ou filantrópicas, definidas em lei, que:

I - comprovem finalidade não-lucrativa e apliquem seus excedentes financeiros em educação;

II - assegurem a destinação de seu patrimônio a outra escola comunitária, filantrópica ou confessional, ou ao Poder Público, no caso de encerramento de suas atividades.

$\S 1^{\circ}$ - Os recursos de que trata este artigo poderão ser destinados a bolsas de estudo para o ensino fundamental e médio, na forma da lei, para os que demonstrarem insuficiência de recursos, quando houver falta de vagas e cursos regulares da rede pública na localidade da residência do educando, ficando o Poder Público obrigado a investir prioritariamente na expansão de sua rede na localidade.

$\S 2^{\circ}$ - As atividades universitárias de pesquisa e extensão poderão receber apoio financeiro do Poder Público. 
promulgada em 1996 (Lei 9.394/1996), tem uma redação prejudicial às comunitárias, pois as considera uma modalidade das instituições privadas. No art. $19^{17}$, a lei estabelece apenas duas categorias de instituições de ensino: públicas e privadas, na linha da clássica dicotomia público/privado. O art. $20^{18}$ explicita as modalidades de instituições privadas: I - particulares, II - comunitárias, III confessionais e IV - filantrópicas. As comunitárias, portanto, não conseguiram fazer valer sua especificidade nesse importante documento legal da educação, que constitui uma das fontes de confusão entre o comunitário e o privado.

Na esteira da LDB, o Plano Nacional de Educação (Lei 10.172, de 9/01/2001), elaborado com base naquelas diretrizes, conferiu pouca relevância ao modelo comunitário. O Plano contém, é verdade, uma recomendação de incentivo às comunitárias: ". Oferecer apoio e incentivo governamental para as instituições comunitárias sem fins lucrativos, preferencialmente aquelas situadas em localidades não atendidas pelo Poder Público, levando em consideração a avaliação do custo e a qualidade do ensino oferecido." Porém, essa recomendação teve poucas consequências práticas.

Paralelalmente, o governo Fernando Henrique Cardoso desencadeou um debate na década de 1990 sobre o público não estatal que passou ao largo das comunitárias. Em 1995, foi aprovado o Plano Diretor da Reforma do Aparelho de Estado, em que a categoria do público não estatal foi utilizada na lógica da minimização do Estado. Em decorrência dessa reforma foram criados dois mecanismos legais que constituem o atual marco do público não estatal do país: a Lei das Organizações Sociais (Lei $n^{\circ}$ 9.637, de 15/05/1998) e a Lei das Organizações da Sociedade Civil de Interesse Público - OSCIPs (Lei ${ }^{\circ}$ 9.790, de 23/03/1999). Nenhum desses mecanismos contempla as instituições comunitárias. As Organizações Sociais destinam-se à privatização de atividades exercidas pelo Estado, o que foge totalmente das características das comunitárias. A lei das OSCIPs exclui explicitamente, no art. $2^{\circ}$, "as escolas privadas dedicadas ao ensino formal não gratuito e suas mantenedoras", assim como "as instituições hospitalares privadas não gratuitas e suas mantenedoras".

17 Art. 19. As instituições de ensino dos diferentes níveis classificam-se nas seguintes categorias administrativas:

I - públicas, assim entendidas as criadas ou incorporadas, mantidas e administradas pelo Poder Público;

II - privadas, assim entendidas as mantidas e administradas por pessoas físicas ou jurídicas de direito privado.

18 Art. 20. As instituições privadas de ensino se enquadrarão nas seguintes categorias:

I - particulares em sentido estrito, assim entendidas as que são instituídas e mantidas por uma ou mais pessoas físicas ou jurídicas de direito privado que não apresentem as características dos incisos abaixo;

II - comunitárias, assim entendidas as que são instituídas por grupos de pessoas físicas ou por uma ou mais pessoas jurídicas, inclusive cooperativas de pais, professores e alunos, que incluam em sua entidade mantenedora representantes da comunidade;

III - confessionais, assim entendidas as que são instituídas por grupos de pessoas físicas ou por uma ou mais pessoas jurídicas que atendem a orientação confessional e ideologia específicas e ao disposto no inciso anterior; IV - filantrópicas, na forma da lei. 
O terceiro momento do debate é a primeira década do século XXI. No processo de discussão da Reforma Universitária desencadeado em 2004, as universidades comunitárias reivindicaram a substituição da díade público/ privado pela tríade público/comunitário/privado. E obtiveram êxito parcial. O Projeto de Reforma Universitária ${ }^{19}$ enviado pelo governo ao Congresso estabelece no art. $8^{\circ}$ três categorias de instituições de ensino superior: públicas, comunitárias e particulares. Embora se trate apenas de um projeto de lei, que enquanto projeto não produz efeitos práticos, é uma sinalização de que o governo começa a se posicionar em favor da superação da simplificação público $\mathrm{x}$ privado, tomando o comunitário como um modelo diferenciado. Ainda na esfera das iniciativas do governo e no mesmo sentido, vale mencionar o consistente estudo de um grupo de juristas convidados pelo Ministério do Planejamento, Orçamento e Gestão para apresentar uma proposta de nova estrutura orgânica para o funcionamento da Administração Pública Federal e das suas relações com entes de colaboração. O anteprojeto apresentado pelos juristas considerou "altamente relevante" incluir no instrumento que trata da organização da administração publica o tratamento a ser dado aos entes de colaboração, entidades que "embora instituídas no âmbito não estatal - ainda que, em alguns casos, com impulso estatal - desenvolvem atividades de interesse público, que as habilitam a atuar como parceiras do Estado. Elas estão a meio caminho entre o estatal e o não estatal, gerindo, muitas delas, verbas públicas". ${ }^{20}$ Os entes de colaboração indicados no documento são as organizações não governamentais, mas a lógica dos juristas é plenamente compatível com os pressupostos de um marco legal das comunitárias.

A partir de 2008, as entidades representativas das universidades comunitárias gaúchas e catarinenses (COMUNG e ACAFE) tomaram a iniciativa de formular e propor ao Governo Federal e ao Congresso Nacional um projeto de lei das instituições comunitárias. Por ação da Associação Brasileira das Universidades Comunitárias - ABRUC, essa mobilização foi incorporada em 2009 por todas as entidades representativas das universidades comunitárias brasileiras, incluindo a Associação Nacional de Educação Católica do Brasil - ANEC e a

19 Disponível em: <http://www.educafro.org.br/seppaa/downloads/Novo_ante_projeto_da_Reforma. pdf>. Acesso em: 29 de set. 2007

20 A comissão de juristas foi constituída por: Almiro do Couto e Silva, Carlos Ari Sundfeld, Floriano de Azevedo Marques Neto, Paulo Eduardo Garrido Modesto, Maria Coeli Simões Pires, Sergio de Andréa e Maria Sylvia di Pietro. O estudo está disponível em:

$<$ http://www.planejamento.gov.br/secretarias/upload/Arquivos/seges/comissao_jur/arquivos/090729_seges_Arq_leiOrganica.pdf.> Acesso em: 12 dez. 2009 
Associação Brasileira de Instituições Educacionais Evangélicas - ABIEE. De forma inédita, as comunitárias unificam seu discurso e sua ação em prol de um marco legal pelo qual o Estado e a sociedade brasileira passem a reconhecêlas como instituições com características distintas das privadas, ou seja, como públicas não estatais. ${ }^{21}$

\section{O COMUNITÁRIO EM TEMPOS DE PÚBLICO NÃO ESTATAL}

Público significa "o que é comum, pertence a todos, é do povo, pelo que, opondo-se a privado, se mostra que não pertence nem se refere ao indivíduo ou ao particular" (SILVA, 2000, p. 661). A esfera pública inclui as questões da coletividade, que estão para além do indivíduo, da família e dos grupos restritos. O público é mais abrangente que o estatal. Ele manifesta-se em duas modalidades: público estatal e público não estatal. Apenas num hipotético "Estado total", em que o Estado fosse o sujeito de todas as iniciativas coletivas, é possível pensar em uma identificação plena entre um e outro. Em sociedades complexas e pluralistas, além dos entes estatais, o público inclui uma gama de organizações e instituições que prestam serviços de interesse coletivo, ou seja, são públicas não estatais. (BRESSER PEREIRA, 1997)

O entendimento de que público é aquilo que pertence a todos, ao povo, está na raiz do postulado de que o comunitário é uma das formas do público, do público não estatal.

A Constituição Federal contém os elementos que sustentam essa construção. A educação comunitária está contemplada no artigo 213, onde se estabelece a possibilidade de repasse de recursos públicos para as instituições comunitárias, confessionais e filantrópicas. O artigo 206, IV, ao tratar do ensino público, estabelece que o mesmo deve ser gratuito nos "estabelecimentos oficiais", o que autoriza a distinção entre estabelecimentos públicos estatais e não estatais (MARTINS, 2008, p. 126). Em sentido semelhante, ao regrar a comunicação social o art. 223 distingue o privado, o público e o estatal: “Art. 223. Compete ao Poder Executivo outorgar e renovar concessão, permissão e autorização para o serviço de radiodifusão sonora e de sons e imagens, observado o princípio da complementaridade dos sistemas privado, público e estatal." Diversos autores entendem que o sistema público de radiodifusão compreende especialmente a radiodifusão comunitária e universitária. E, acima de tudo, a Constituição

21 A mobilização das comunitárias em prol da conquista do marco legal, incluindo o texto do projeto de lei apresentado ao Poder Público, pode ser conferida no site $<$ www.comunitarias.org.br. $>$ 
Federal prevê com muita ênfase a cooperação entre Estado e sociedade na garantia dos direitos sociais e reconhece a participação da sociedade civil na execução das políticas sociais: saúde (art. 197), assistência social (art. 204), educação (art. 205), cultura (art. 216), desporto (art. 217), meio ambiente (art. 225), comunicação social (art. 223).

A legislação infraconstitucional estabelece variados mecanismos jurídicos que permitem a pessoas ou entidades privadas sem fins lucrativos o acesso a recursos estatais: subvenção social, auxílio, contribuição, convênio, termo de parceria, imunidade de impostos, imunidade de contribuições sociais, isenção, incentivo fiscal ao doador e voluntariado. (SILVA; JACCOUD; BEGHIN, 2005)

Tendo em vista a diversidade das iniciativas comunitárias cabe questionar se todas preenchem os requisitos do público não estatal. A identificação pura e simples do comunitário com o público não estatal não é pertinente: são conceitos com origens distintas, sua abrangência não é a mesma e os agentes identificados com um não assumem necessariamente o outro. Tanto do ponto de vista conceitual como legal cabe distinguir as categorias. Como formulação provisória, sugere-se que sejam entendidas como públicas não estatais as organizações e instituições comunitárias

- criadas e mantidas pela sociedade civil organizada;

· orientadas ao interesse coletivo, não pela lógica do mercado;

· autônomas em relação ao Estado;

- que assumam a identidade pública não estatal;

· adequadas aos princípios da administração pública.

A questão da autonomia das instituições é central. São comuns organizações não oficialmente estatais, mas que gravitam na órbita estatal e são sustentadas pelo Estado, ou organizações que ao prestarem serviços para o Estado criam uma ampla dependência de tal relação. Tais organizações são mais propriamente semiestatais do que não estatais. No caso das instituições comunitárias de educação superior brasileiras, embora todas mantenham relação permanente com entes públicos e muitas abriguem representantes governamentais em suas instâncias deliberativas, elas preservam sua autonomia no plano decisório e financeiro. É o que faz delas instituições não estatais.

A adequação das comunitárias aos princípios da administração pública carrega uma tarefa que não é simples: a elucidação da aplicabilidade às instituições comunitárias dos preceitos, princípios e finalidades que a Constituição 
e a legislação estabelecem para a administração pública. Em outras palavras: as comunitárias preenchem os requisitos do público? Pode-se apontar como requisitos mínimos os princípios constitucionais da administração pública, estabelecidos no art. 37 da Constituição: legalidade, impessoalidade, moralidade, publicidade e eficiência. Esse exame requer a análise de outras questões: a legislação existente é apropriada para delimitar o que é público num sentido não estatal? Os princípios da administração pública são aplicáveis aos entes comunitários da mesma forma que aos entes estatais ou por analogia? Uma aplicação idêntica desses princípios não parece adequada, em face das características estruturalmente distintas dos entes comunitários e estatais, e porque a doutrina referente à administração pública está orientada pela equalização do público ao estatal. Aplicar de forma direta os regramentos da administração pública estatal às instituições comunitárias descaracterizará o modelo comunitário e retirará a potência política do conceito de público não estatal.

A aplicação analógica dos princípios da administração pública às comunitárias, como parte de um processo de construção de um novo direito público, não garante que todas sejam reconhecidas como públicas. Levando em conta as várias referências históricas da educação comunitária no Brasil tratadas neste texto e a diversidade de características constatadas é possível que apenas uma parte preencha os requisitos do público não estatal.

\section{CONCLUSÃO}

Comunidade e comunitário são categorias com grande relevância nos dias atuais. O discurso comunitário vem sendo constantemente retomado por organizações sociais, instituições e agentes com diferentes orientações ideológicas.

A rememoração histórica das experiências de educação comunitária no Brasil revela uma grande diversidade de características. Algumas delas assumiram a concepção de que o comunitário é uma expressão do público não estatal, uma categoria importante no debate político atual face ao esgotamento dos modelos estatista e privatista de organização sócio-político-econômica.

Pensar o comunitário como público não estatal não é, pois, uma tarefa simples. Na cultura política e na ordem legal brasileiras prevalece ainda a tendência reducionista de identificar o público com o estatal. A afirmação do público não estatal e o reconhecimento do comunitário como público não estatal requerem uma construção política, que passa pelos planos cultural, teórico e jurídico. O comunitarismo, especialmente na formulação de Amitai Etzioni, apresenta um relevante repertório conceitual para esse debate. 
Mais que em momentos anteriores, talvez estejam maduras as condições para que a discussão resulte num marco legal apropriado à realidade e ao potencial das comunitárias, em vista da mobilização nacional dessas instituições. As macro-condições políticas foram delineadas acima: o esgotamento dos modelos estatista e privatizante de Estado. O processo político dirá se os agentes políticos estão preparados para avançar na definição do novo modelo de Estado, que favoreça a cooperação entre os entes estatais, os da sociedade civil e as organizações privadas. E ao meio acadêmico cabe a tarefa de elucidar e aprofundar a abordagem do caráter público das instituições comunitárias.

\section{REFERÊNCIAS}

ADÁN, José Perez (Coord.). Comunitarismo: cultura de solidaridad. Madrid: Sekotia, 2003.

AHLERT, Alvori. Igreja e escola: desafios atuais para as escolas comunitárias da Igreja Evangélica de Confissão Luterana no Brasil (IECLB) e sua rede associativa. Actualidades Investigativas en Educación, Costa Rica, set. /dez. 2006.

AMMANN, Safira B. Ideologia do desenvolvimento de comunidade no Brasil. 10. ed. São Paulo: Cortez, 2003.

ARENDT, Hannah. O sistema totalitário. Lisboa: Dom Quixote, 1978.

BATISTA NETO, José. Professora comunitária: trajetória social e tipologia de um mito. 1999. Disponível em: <http://www.fundaj.gov. br/licitacao/artigoprofessoracomunitaria.pdf.> Acesso em: 14 set. 2009.

BAUMAN, Zygmunt. Comunidade: a busca por segurança no mundo atual. Rio de Janeiro: Jorge Zahar, 2003.

CARDOSO, Aparecida. Gestão participativa numa escola comunitária. 1995. Dissertação (Mestrado) - Universidade Estadual de Campinas, Campinas, 1995. 
DOWBOR, Ladislau. Democracia econômica. Petrópolis: Vozes, 2009.

ETZIONI, Amitai. Communitarianism. In: CHRISTENSEN, Karen; LEVINSON, David (ed.). Encyclopedia of community: from the village to the virtual world. Sage Publications, 2003. v.1, p. 224-228.

FOLLMANN, José Ivo. As universidades confessionais e a sua natureza comunitária e pública não estatal. In: SCHMIDT, João P. (Org.) Instituições comunitárias: instituições públicas não-estatais. Santa Cruz do Sul: Edunisc, 2009. p. 108-115.

FRANTZ, Walter; SILVA, E. W. As funções sociais da universidade: o papel da extensão e a questão das comunitárias. Ijuí: Ed. Unijuí, 2002.

GADOTTI, Moacir. Universidade estatal, universidade comunitária: dois perfis em construção da universidade brasileira. 1995. Disponível em: $<$ http://www.paulofreire.org.> Acesso em: 15 out. 2009.

GADOTTI, Moacir; GUTIÉRREZ, Francisco (orgs). Educação comunitária e economia popular. São Paulo: Cortez, 1993. Coleção Questões da nossa Época, v. 25.

HOBSBAWN, Eric. Socialism has failed. Now capitalism is bankrupt. So what comes next? The Guardian, Reino Unido, 13 abr. 2009.

LIMA, Luiz G. Contribuições das instituições de educação superior da Associação Catarinense de Fundações Educacionais a Santa Catarina e ao Brasil. In: SCHMIDT, João P. (Org.). Instituições comunitárias: instituições públicas não-estatais. Santa Cruz do Sul: Edunisc, 2009. p. 93-107.

LUCHESE, Terciane A. O processo escolar entre imigrantes da região colonial italiana do RS - 1875-1930. 2007. Tese (Doutorado) - Programa de Pós-Graduação em Educação, Universidade do Vale do Rio dos Sinos, 2007.

MARTINS, Geraldo M. Universidade federativa autônoma e comunitária. Brasília: Athalaia, 2008. 
MOURA, Laercio D. A educação católica no Brasil. São Paulo: Loyola, 2000.

NISBET, Robert. Os filósofos sociais. Brasília: Edunb, 1982. Comunidade. In: FORACCHI, M. M.; MARTINS, J. S. Sociologia e sociedade: leituras de introdução à sociologia. Rio de Janeiro: LTC, 1998. p. 255-262.

PERES, C.; FERREIRA, L. Demonstração do valor adicionado DVA aplicada às escolas católicas confessionais: um estudo de caso na União Norte brasileira de Educação e Cultura - UNBEC. Disponível em: http://www.contabeis.ucb.br/sites/000/96/00000047.pdf. . . Acesso em: 15 set. 2009

POSTER, Cyril; ZIMMER, Jürgen (Orgs.). Educação comunitária no terceiro mundo. Campinas: Papirus, 1995.

PUTNAM, Robert. Comunidade e democracia: a experiência da Itália moderna. Rio de Janeiro: Fundação Getúlio Vargas, 1996.

RAMBO, Arthur B. A escola comunitária teuto-brasileira católica. São Leopoldo: Ed. Unisinos, 1994.

SANTOS, Marlene S. Formação continuada e professores de escolas comunitárias: sentidos do percurso formativo. 2007. Dissertação (Mestrado) - Universidade Federal da Bahia, Salvador, 2007.

SCHMIDT, João P. (org.) Instituições comunitárias: instituições públicas não-estatais. Santa Cruz do Sul: Edunisc, 2009a.

$$
\text { . O novo Estado, o público não estatal e as instituições }
$$

comunitárias. In: DIREITOS sociais e políticas públicas - desafios contemporâneos. Santa Cruz do Sul: Edunisc, 2009b. v.9, p. 2784-2812.

SHORE, Cris. Comunidade. In: OUTHWAITE, William (Ed.). Dicionário do pensamento social do século XX. Rio de Janeiro: Jorge Zahar, 1996. 
SILVA, De Plácido. Vocabulário jurídico. Rio de Janeiro: Forense, 2000.

SILVA, F.; JACCOUD, L; BEGHIN, N. Políticas sociais no Brasil participação social, conselhos e parcerias. In: JACCOUD, L. (org.) Questão social e políticas sociais no Brasil contemporâneo. Brasília: IPEA, 2005. p. 373-408.

SOUZA, Maria L. Desenvolvimento de comunidade e participação. São Paulo: Cortez, 1996.

SOUZA, Robson S. R. O comunitarismo cristão e suas influências na política brasileira - uma revisão bibliográfica sobre o comunitarismo católico no Brasil. Horizonte, Belo Horizonte, v. 6, n. 12, p.41-68, jun. 2008.

SCHNEIDER, Joni R. Escola comunitária: trama entre sujeitos e instituição. Dissertação (Mestrado). Escola Superior de Teologia, São Leopoldo, 2008.

SILVA, Ronalda B. Educação comunitária: além do estado e do mercado? A experiência da Campanha Nacional de Escolas da Comunidade - CNEC (1985-1998). São Paulo: Autores Associados, 2003.

TOURAINE, Alain. O que é democracia? Petrópolis: Vozes, 1996.

VIEIRA, Liszt. Cidadania e sociedade civil no espaço público

democrático. 2005. Disponível em: < http://empreende.org.br.> Acesso em: 27 nov. 2009.

VOGT, Olgario. Capital social e instituições comunitárias no Sul do Brasil. In: SCHMIDT, João P. (Org.). Instituições comunitárias: instituições públicas não-estatais. Santa Cruz do Sul: Edunisc, 2009. p. 56-73.

WARE, Caroline F. Organização e desenvolvimento da comunidade: trabalhos práticos. São Paulo: Cultrix, 1970. 